\title{
iERBMF
}

\section{Does Emotional Intelligence Influences the Leadership Style?}

\author{
Dr. Sindu Bharath ${ }^{1}$, Dr P. Nagesh ${ }^{2}$, Dr T S Nanjundeswaraswamy ${ }^{3}$ \\ 1,2 JSS Centre for Management Studies, JSS Science \& Technology University, \\ Mysore - 570 006, Karnataka, India. \\ ${ }^{3}$ Department of Mechanical Engineering, JSS Academy of Technical Education, Bangalore \\ 560060, Karnataka, India
}

\begin{abstract}
Leaders play pivotal role in managing all the resources in an efficient and effective manner particularly human resources. Predominantly in IT sector, where employees are considered to be the organization's invaluable asset. The present research aims to examine the relationship between Emotional Intelligence (EI) and leadership styles. To fulfil the stated objective, data were collected through structured questionnaire; the instrument is validated using statistical techniques such as Exploratory Factor Analysis (EFA), Confirmatory Factor Analysis (CFA) and reliability of instrument is measured to verify the credibility of the designed instrument. Goleman (2007) EI measuring scale and Kurt Lewin's Leadership scale is adopted. Structural equation modelling (SEM) is carried out using AMOS to explore the relationship between the variables considered in the present study. With due consideration of average value of individual employee's perception, it is noted that 53.8 percent of the surveyed employees have high level of emotional intelligence, while 46.2 percent of surveyed employees have low level of emotional intelligence. Type of the leadership style is classified as Autocratic Leadership, Democratic Leadership and Laissez-faire. Accordingly, out of 316 employees from IT Sector $43.4 \%$ of the employees' perception exhibits Laissez-faire type of the leadership styles, $40.2 \%$ displays autocratic leadership styles, while $16.5 \%$ respondents exhibit democratic leadership styles. The results indicate that there is a relationship between the EI and leadership style of employees. Thus, the level of EI needs to be strengthened through persistence, practice and feedback mechanism from coaches and experts in an organisation.
\end{abstract}

Keywords: Emotional Intelligence, Employee perception, Information Technology, Leadership style, Team Leaders 